\title{
THE
}

\section{Dynamics and Chemistry of Marine Stratocumulus (DYCOMS) Experiment}

D. H. Lenschow

I. R. Paluch

A. R. Bandy

R. Pearson Jr.

S. R. Kawa

See next page for additional authors

Follow this and additional works at: https://digitalcommons.uri.edu/gsofacpubs

\section{Citation/Publisher Attribution}

Lenschow, D. H., Paluch, I. R., Bandy, A. R., Pearson Jr., R., Kawa, S. R., Weaver, C. J., ...Driedger III, A. R. (1988). Dynamics and Chemistry of Marine Stratocumulus (DYCOMS) Experiment. Bull. Amer. Meteor. Soc., 69(9), 1058-1067. doi: 10.1175/1520-0477(1988)0692.0.C0;2 Available at: https://doi.org/10.1175/1520-0477(1988)0692.0.C0;2

This Article is brought to you for free and open access by the Graduate School of Oceanography at DigitalCommons@URI. It has been accepted for inclusion in Graduate School of Oceanography Faculty Publications by an authorized administrator of DigitalCommons@URI. For more information, please contact digitalcommons@etal.uri.edu. 


\section{Authors}

D. H. Lenschow, I. R. Paluch, A. R. Bandy, R. Pearson Jr., S. R. Kawa, C. J. Weaver, B. J. Huebert, J. G. Kay,

D. C. Thornton, and A. R. Driedger III 


\section{Dynamics and Chemistry of Marine Stratocumulus (DYCOMS) Experiment}

D. H. Lenschow, I. R. Paluch,

A. R. Bandy, ${ }^{2}$ R. Pearson, Jr., S. R. Kawa, ${ }^{3}$ C. J. Weaver, ${ }^{3}$ B. J. Huebert, ${ }^{4}$ J. G. Kay, ${ }^{5}$ D. C. Thornton, ${ }^{5}$ and A. R. Driedger III $^{5}$

\section{Abstract}

A combined atmospheric chemistry-meteorology experiment, the Dynamics and Chemistry of the Marine Stratocumulus (DYCOMS), was carried out during the summer of 1985 over the eastern Pacific Ocean using the NCAR Electra aircraft. The objectives were to 1) study the budgets of several trace reactive species in a relatively pristine, steadystate, horizontally homogeneous, well-mixed boundary layer capped by a strong inversion and 2) study the formation, maintenance and dissipation of marine stratocumulus that persists off the California coast (as well as similar regions elsewhere) in summer. We obtained both mean and turbulence measurements of meteorological variables within and above the cloud-capped boundary layer that is typical of this region. Ozone was used successfully as a tracer for estimating entrainment rate. We found, however, that horizontal variability was large enough for ozone that a correction needs to be included in the ozone budget for the horizontal displacement due to turns even though the airplane was allowed to drift with the wind. The time rate-of-change term was significant in both the ozone and radon budgets; as a result, a considerably longer time interval than the two hours used between sets of flight legs would be desirable to improve the measurement accuracy of this term.

\section{Introduction}

As pointed out by Randall et al. (1984) and Albrecht et al. (1988), marine stratiform clouds play an important role in the earth's climate system because of their effects on its radiation budget. For this reason, as well as concerns about local forecasting of stratus and fog, there has been considerable interest in gaining a better understanding of their formation, maintenance, and dissipation. At the same time, the regions of the globe characterized by marine stratiform clouds present unique opportunities for research on problems of global tropospheric chemistry. In recent years, there has been an increased awareness of the influence of human activity on the chemistry of the global atmosphere. Intensive studies of urban air pollution, the chemistry of the stratosphere, and some exploratory studies of

\footnotetext{
${ }^{1}$ National Center for Atmospheric Research, (sponsored by the National Science Foundation) Boulder, Colorado.

${ }^{2}$ Drexel University, Philadelphia, Pennsylvania.

${ }^{3}$ Colorado State University, Fort Collins, Colorado.

${ }^{4}$ The University of Rhode Island, Narragansett, Rhode Island.

${ }^{5}$ Drexel University, Philadelphia, Pennsylvania.
}

(C) 1988 American Meteorological Society the nonurban troposphere and the effects of trace species on climate have helped to develop a basic understanding of atmospheric chemistry. Yet, many fundamental questions regarding the basic behavior of trace reactive species remain unanswered. As a result, the atmospheric chemistry community has called for a Global Tropospheric Chemistry Program (GTCP) (Global Tropospheric Chemistry: A Plan for Action, 1984). This program calls for a series of observational studies to evaluate sources and sinks, distributions, transports, and transformations of chemical substances in the atmosphere. The studies involve, for the most part, measurements of trace atmospheric species embedded in an observational network of meteorological measurements in designated regions of interest. One of these regions is the marine atmospheric boundary layer.

The stratiform cloud regions to the west of continents from about $20^{\circ}$ to $40^{\circ}$ latitude in summertime form in response to strong subsidence in the atmosphere over an upwelling (and therefore relatively cold) ocean. These regions offer a nearly laboratory-like setting for studying the chemistry of pristine air in a well-mixed boundary layer capped by a strong inversion, with persistent mean winds and cloud cover, few weather disturbances, and minimal diurnal variability.

For these reasons, a combined atmospheric chemistrymeteorology experiment, called the Dynamics and Chemistry of the Marine Stratocumulus (DYCOMS), was carried out over the eastern Pacific Ocean from 30 July to 21 August 1985. The primary research platform was the NCAR Electra aircraft. This experiment coincided with a preliminary FIRE (The First ISCCP [International Satellite Cloud Climatology Project] Regional Experiment) experiment carried out with the NOAA P-3 aircraft. Both aircraft were based at North Island Naval Air Station, San Diego, California, and several coordinated missions were carried out in the primary research area, which was more than $300 \mathrm{~km}$ west of San Diego.

A major objective of DYCOMS was to evaluate budgets of trace species from aircraft measurements by the technique discussed by Lenschow (1984). This technique is best implemented in a region of horizontal homogeneity, with a wellmixed steady-state boundary layer capped by an inversion strong enough to inhibit cloud penetration. Such an idealization does not occur in our atmosphere, but the region studied here is closer than most. The ocean-surface temperature distribution, shown in Fig. 1, indicates that for most of the flight legs, the mean horizontal gradient in surface temperature was less than $0.01 \mathrm{~K} \cdot \mathrm{km}^{-1}$. 
TABLE 1. Description of DYCOMS Electra Flights. Values of $\bar{T}_{50 \mathrm{~m}}$ are average temperatures at $50 \mathrm{~m}$ height. Other overbarred quantities are mixed-layer averages $-\bar{q}_{w}$ is total water $\bar{\theta}_{l}$ is liquid water potential temperature, $\bar{O}_{3}$ is mean ozone concentration, $\overline{W S}$ and $\overline{W D}$ are mean wind speed and direction, and $\bar{q}_{l}$ (top) is the estimated maximum liquid water content at cloud top.

\begin{tabular}{|c|c|c|c|c|c|c|c|c|c|c|}
\hline Flight Number & 1 & 2 & 3 & 4 & 5 & 6 & 7 & 8 & 9 & 10 \\
\hline $\begin{array}{l}\text { Time } \\
\text { (PDT) }\end{array}$ & $\begin{array}{c}10: 57 \\
\text { to } \\
17: 57\end{array}$ & $\begin{array}{c}09: 02 \\
\text { to } \\
16: 04\end{array}$ & $\begin{array}{c}09: 56 \\
\text { to } \\
16: 47\end{array}$ & $\begin{array}{c}09: 55 \\
\text { to } \\
17: 09\end{array}$ & $\begin{array}{c}09: 49 \\
\text { to } \\
17: 07\end{array}$ & $\begin{array}{c}10: 41 \\
\text { to } \\
15: 37\end{array}$ & $\begin{array}{c}10: 16 \\
\text { to } \\
17: 33\end{array}$ & $\begin{array}{c}09: 02 \\
\text { to } \\
17: 10\end{array}$ & $\begin{array}{c}10: 56 \\
\text { to } \\
18: 03\end{array}$ & $\begin{array}{c}05: 24 \\
\text { to } \\
12: 35\end{array}$ \\
\hline Date & $7 / 30$ & $8 / 2$ & $8 / 4$ & $8 / 7$ & $8 / 9$ & $8 / 13$ & $8 / 16$ & $8 / 18$ & $8 / 19$ & $8 / 21$ \\
\hline $\begin{array}{l}\text { Location } \\
\text { (Lat/Long) }\end{array}$ & $31 / 123$ & $33 / 122$ & $32 / 120$ & $31 / 122$ & $31 / 123$ & $\begin{array}{c}32 / 121 \\
\text { to } \\
34 / 126\end{array}$ & $31 / 122$ & $34 / 123$ & $\begin{array}{c}32 / 121 \\
\text { to } \\
24 / 124\end{array}$ & $31 / 123$ \\
\hline $\begin{array}{l}\bar{T}_{50 m}\left({ }^{\circ} \mathrm{C}\right) \\
\bar{q}_{w}\left(\mathrm{~g} \mathrm{~m}^{-3}\right)\end{array}$ & $\begin{array}{l}17.5 \\
11.4\end{array}$ & $\begin{array}{l}16.1 \\
10.9\end{array}$ & $\begin{array}{l}16.1 \\
11.2\end{array}$ & $\begin{array}{l}17.8 \\
11.0\end{array}$ & $\begin{array}{l}17.8 \\
10.5\end{array}$ & $\begin{array}{c}17.1 \\
9.8\end{array}$ & $\begin{array}{l}17.9 \\
10.6\end{array}$ & $\begin{array}{l}17.2 \\
10.7\end{array}$ & $\begin{array}{l}19.2 \\
11.5\end{array}$ & $\begin{array}{r}17.2 \\
9.6\end{array}$ \\
\hline$\underline{\theta}_{l}(\mathrm{~K})$ & 289.6 & 288.4 & 288.4 & 290.0 & 290.2 & 289.0 & 291.4 & 289.5 & 291.5 & 289.3 \\
\hline${\overline{\bar{O}_{3}}}_{\text {(ppbv) }}$ & 19.7 & 25.4 & 32.7 & 23.5 & 24.5 & 44.3 & 50.5 & 25.8 & 27.4 & 39.3 \\
\hline$W S\left(\mathrm{~m} \mathrm{~s}^{-1}\right)$ & 9.8 & 9.0 & 5.6 & 8.8 & 7.5 & 4.3 & 5.4 & 7.0 & 7.4 & 6.3 \\
\hline$\overline{W D}$ (DEG) & 342 & 322 & 321 & 340 & 328 & 276 & 308 & 316 & 357 & 349 \\
\hline Cloud top (m) & 733 & 730 & 588 & 880 & 925 & 917 & 1380 & 1034 & 1150 & 1009 \\
\hline Cloud base (m) & 520 & 450 & 440 & 600 & 725 & 900 & 1100 & - & 1130 & 775 \\
\hline $\bar{q}_{l}$ (top) $\left(\mathrm{g} \mathrm{m}^{-3}\right)$ & $0.40^{1}$ & $0.43^{2}$ & $0.27^{3}$ & $0.44^{3}$ & $0.43^{2}$ & $0.17^{4}$ & $0.47^{5}$ & $0.0^{6}$ & 0 to $0.3^{7}$ & $0.46^{2}$ \\
\hline
\end{tabular}

${ }^{1}$ Solid, unbroken stratus

${ }^{2}$ Near solid; occasional breaks

${ }^{3}$ Broken; $6 / 8$ to unbroken coverage

${ }^{4}$ Scattered; clear to $4 / 8$ coverage

${ }^{5}$ Broken, multiple layers

${ }^{6}$ Clear; scattered cirrus

${ }^{7}$ Variable; clear to broken layered.

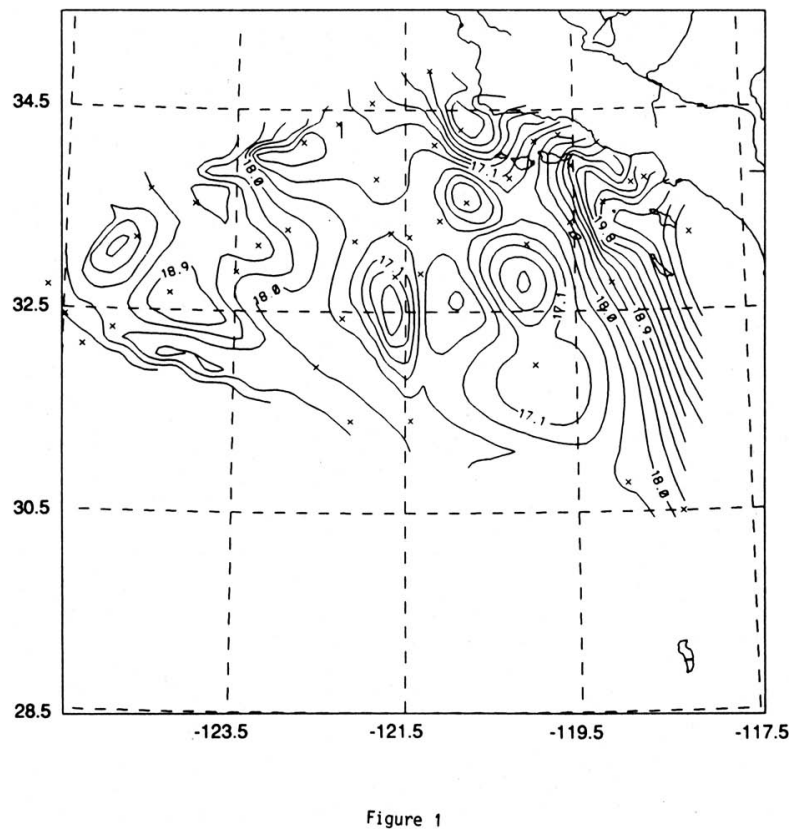

Fig. 1. Surface temperature contours based on bathythermograph measurements obtained from the Scripps Oceanographic Institute Research Vessel Horizon from 2 to 22 August 1985. The " $X$ 's" denote locations of some of the observations, to indicate the approximate location of the ship track.

\section{Description of flights}

A total of 10 research flights (about 70 research flight hours) were conducted; they are briefly described in Table 1 . The typical flight pattern consisted of a ferry out, at 3000-m height, to approximately $300 \mathrm{~km}$ from shore, a sounding down to $\sim 50 \mathrm{~m}$, a set of constant level legs $\sim 15$ minutes in length at: $50 \mathrm{~m}$, midway between the surface and cloud base, $\sim 100 \mathrm{~m}$ above cloud base, $\sim 100 \mathrm{~m}$ below cloud top, at cloud top, and $\sim 100 \mathrm{~m}$ above cloud top. The leg above cloud top was normally repeated twice for a total of $\sim 45$ minutes. On Flights 1 to 5 , the flight legs were crosswind; on Flights 7, 8, and 10 each leg was split into a crosswind and an alongwind segment. After the first set of legs, another sounding to the lowest flight level was carried out and the set of legs was then repeated. A final sounding was conducted from just above the boundary layer down to the lowest flight level, and back up to the return ferry level of $\sim 5000 \mathrm{~m}$. On Flights 6 and 9 attempts to follow estimated air trajectories were made. All the flights were conducted near midday, except Flight 10, which was an early morning one. All the flights were conducted in cloudy or mostly cloudy conditions, except for Flight 8 , which was a clear air flight. Flights 2, 3, 4, 5, and 6 were carried out in coordination with the NOAA P-3; several intercomparison legs were flown on Flights 2 and 3.

\section{Meteorological measurements, data and preliminary results}

The Electra was instrumented to measure the three air-velocity components (using a Litton LTN-51 Inertial Navigation System [INS] and fixed-vane gust probe), air temperature, surface radiation temperature (Barnes PRT-5 radiometer), mean humidity (dew-point hygrometer), humidity fluctuations (Lyman-alpha hygrometer), liquid water (Particle Measuring Systems [PMS] King probe and Johnson-Williams probe), upward and down- 
ward radiation in the ultraviolet, visible, and infrared portions of the spectrum (Eppley hemispheric radiometers), aerosol spectra (PMS ASASP [Active Scattering Aerosol Spectrometer Probe]), and cloud droplet spectra (PMS FSSP [Forward Scattering Spectromer Probe] and 200X probes). Aircraft position and heading were obtained from the INS; additional positional information was obtained from a Loran-C navigational system. Altitude was obtained from both pressure and radio altimeters. Time lapse side-looking 16-mm movie cameras and a forwardlooking video camera recorded visual information. Analog turbulence data (the three air velocity components, air temperature, humidity and ozone) were filtered in flight with a $10-\mathrm{Hz}$ low-pass four-pole Butterworth filter, digitized and recorded at $50 \mathrm{~s}^{-1}$. Subsequently these data were interpolated to $20 \mathrm{~s}^{-1}$ by the technique described by Lenschow and Kristensen (1988). The air velocity components were combined with airplane velocity data from the INS to provide air velocity measurements at $20 \mathrm{~s}^{-1}$ (Lenschow, 1986). Turbulence measurements were used to compute fluxes of temperature, humidity, momentum, and ozone, as well as examine details of the entrainment process at the top of the boundary layer.

For the most part, the meteorological sensors operated satisfactorily. The most notable exceptions were the vane measurements of attack angle and sideslip angle (used to obtain the vertical and lateral wind components) in the vicinity of cloud edge, and fast-response humidity measurements (using the Lyman-alpha hygrometer) during the latter part of Flight 7 . Due to an apparent electrical problem, the vane outputs contained large errors just after entering or leaving a cloud.

A major objective of DYCOMS was to carry out measurements of trace atmospheric species in air that has not recently been modified by species emanating from the continents. One way to investigate the air's past history is to compute air trajectories initialized at the research site during the flights and extending backwards in time. Figure 2 shows an example of trajectory calculations (carried out by Joyce Harris, NOAA Environmental Research Laboratories; the technique is described by Harris, 1982) initialized at $33^{\circ} \mathrm{N}, 121^{\circ} \mathrm{W}$ at $00: 00$ UTC, 10 August 1985. This corresponds to the time and place of Electra Flight 5; trajectories on the other flight days also usually follow a similar southerly to southeasterly path. Figures 3 and 4 are satellite photographs of the research area taken on 9 August 1985.

Figure 2 shows that the path of a parcel just above the inversion goes further north and involves much higher altitudes and lower temperatures than the path of a parcel from below the inversion. The looped trajectory and upward air motion over the Gulf of Alaska indicates that the parcel passed through a cyclonic disturbance four to six days prior to the flight time. Throughout the trajectory, there is no indication that air of recent continental origin has been incorporated into the parcel. This is in agreement with the radon and chemical observations that generally indicate the air in the research area on flight days had not been in contact with continental boundary layer air for at least the previous ten days to two weeks.

The lowest temperature experienced by a parcel originating above the inversion was $-21^{\circ} \mathrm{C}$ at $519 \mathrm{mb}$ (days 5 and 6), which corresponds to a saturation water vapor mixing ratio of $1.4 \times 10^{-3}$. The observed moisture content of the air above the inversion obtained from Flight 5 on 9 August was in the 1 to $2 \times 10^{-3}$ range (Fig. 5), which can be interpreted to show
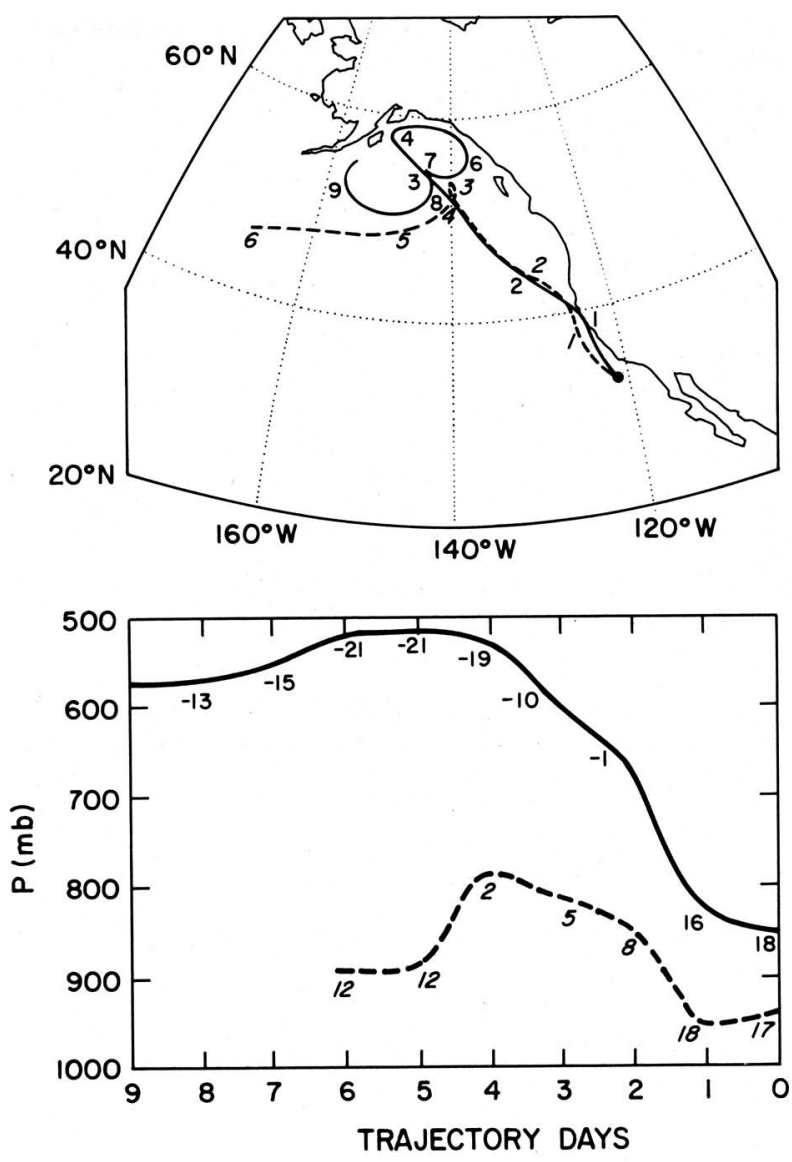

Figure 2

FIG. 2. Air parcel trajectories computed by the technique described by Harris $(1982)$ and initialized at $33^{\circ} \mathrm{N}, 121^{\circ} \mathrm{W}$ at $00: 00$ UTC, 10 August 1985. This corresponds to the time and place of Electra Flight 5; The solid line is the path of a parcel just above the inversion initialized at $\theta=305 \mathrm{~K}$; the dashed line is the path of a parcel in the mixed layer initialized at $\theta=205 \mathrm{~K}$. The numbers adjacent to the trajectories indicate the number of days previous to the initialized day. The lower curve shows the parcel pressure as a function of days previous to the initial trajectory time. The numbers on the curves are temperatures at the end of each day.

that air above the inversion had dried out through the release of precipitation at higher altitudes, and then descended.

Figure 5 shows a sounding obtained from Flight 5 (1749:50 to 1804:00 UTC, 9 August 1985), during which the aircraft descended $3 \mathrm{~km}$ over a horizontal distance of about $100 \mathrm{~km}$. The location of the sounding is shown on the satellite images presented in Figs. 3 and 4. Profiles from other stratiform days are very similar, except for some cases (most notably Flights 7 and 9) which show, on some soundings, a decoupling of the cloud layer from the boundary layer as noted by Nicholls (1984). The potential temperature profile (THTA) shows a well-defined inversion at $916 \mathrm{mb}$. Above the inversion there are large variations in ozone concentration (03F50) and the air is dry, as indicated by the total-water mixing ratio (QTOT), which includes water both in the vapor phase and in the liquid phase. Below the inversion the potential temperature, ozone, and, to a lesser extent, the total-water mixing ratio profiles are nearly 


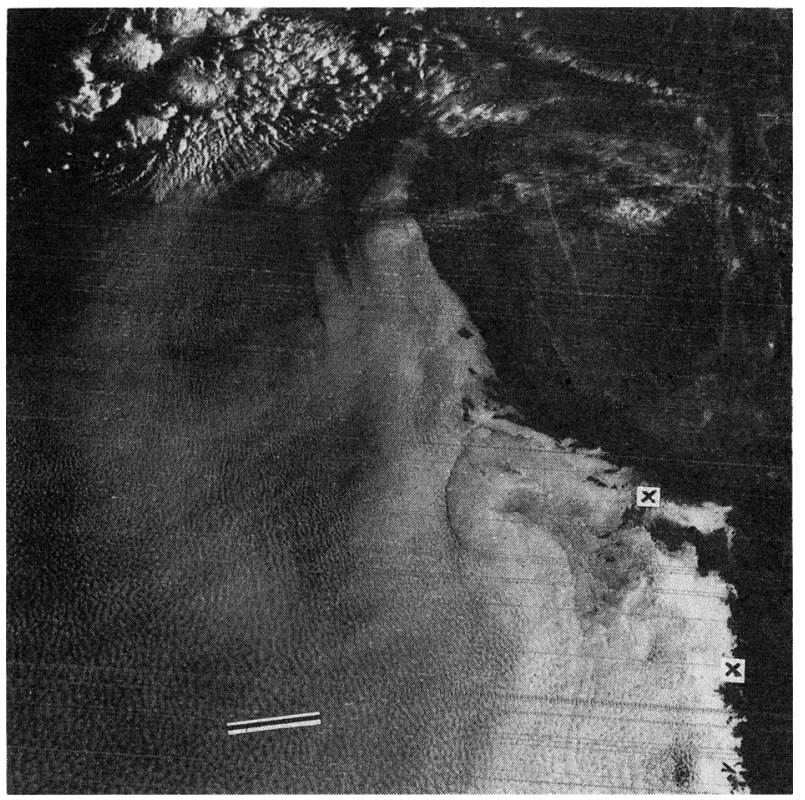

FIG. 3. Satellite image at 14:11 UTC, 9 August 1985 produced from U.S. Air Force (USAF) DMSP (Defense Meteorological Satellite Program) film transparencies archived for National Oceanic and Atmospheric Administration (NOAA)/National Environmental Satellite, Data, and Information Service (NESDIS) at the University of Colorado, CIRES/ National Snow and Ice Data Center, Campus Box 449, Boulder, CO

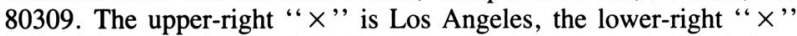
is San Diego and the line in the lower-center of the image is the airplane flight track during the sounding shown in Fig. 5, which is $500 \mathrm{~km}$ WSW of San Diego.

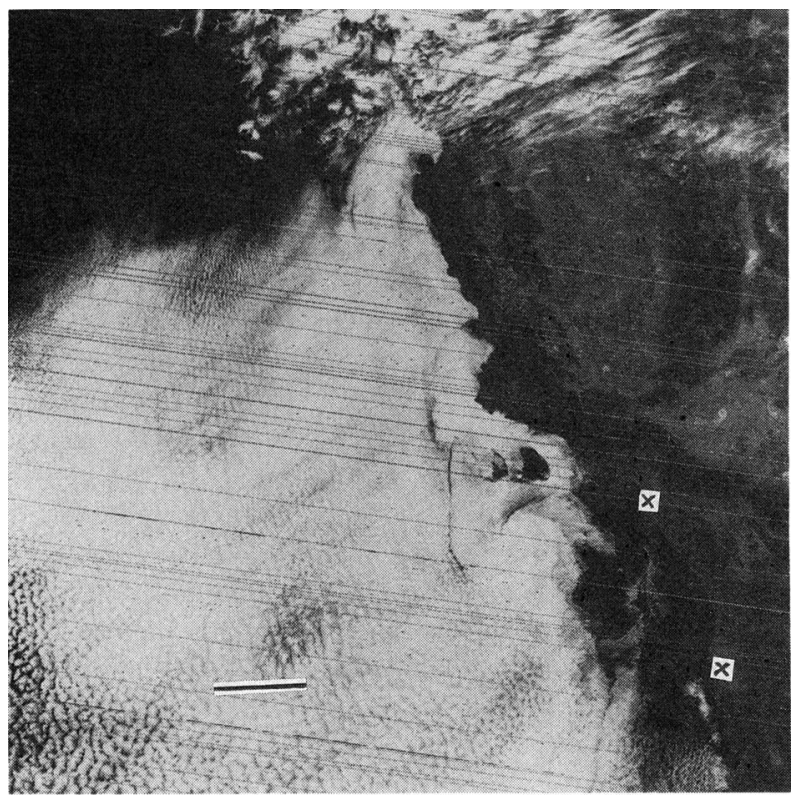

FIG. 4. Satellite image at 18:32 UTC, 9 August 1985 from USAF DMSP film transparencies archived for NOAA/NESDIS at the University of Colorado. The upper-right " $x$ " is Los Angeles, the lowerright " $x$ " is San Diego and the line in the lower-center of the image is the airplane flight track (see Fig. 3). constant, as is expected in a well-mixed boundary layer. ${ }^{6}$ The mixed layer below the inversion is capped by a thin cloud layer, as indicated by the King probe liquid water measurements (CPLWC). The wind shows large fluctuations indicative of turbulence below the inversion in the west (UI), south (VI), and vertical (WI) components, whereas above the inversion the vertical component is nearly zero and the fine-scale horizontal fluctuations are significantly damped.

The structure of the inversion is shown in more detail in Fig. 6 , in which a 6-mb segment encompassing the inversion has been expanded. The potential temperature (THTA), ozone (O3F50) and total-water mixing ratio (QTOT) profiles show fluctuations suggestive of nonuniform mixing across the inversion and/or local variations in the inversion height (the data segment here represents a 60 -m descent over a horizontal distance of about $2 \mathrm{~km}$ ). In addition to the potential temperature, the figure also shows the liquid-water potential temperature, $\theta_{L}$, (THTAL) defined by $\theta_{L}=\theta-L q_{L} / c_{p}$, where $\theta$ is the potential temperature, $q_{L}$ is the liquid water mixing ratio, $L$ is the latent heat of condensation, and $c_{p}$ is the specific heat of dry air at constant pressure. It can be shown that for altitudes typical of marine stratocumulus layers, this temperature remains nearly constant during adiabatic altitude changes, and it is conserved during mixing. For the present data the liquidwater potential temperature, $\theta_{L}$, is more suitable for studying mixing across the inversion than the commonly used equivalent potential temperature, $\theta_{e}$, because the former is easier to compute and it is less sensitive to errors in measurement. ${ }^{7}$ We have computed $\theta_{L}$ using temperature from the fast-response thermometer and liquid water from the CSIRO liquid water probe ${ }^{8}$ data (corrected for baseline drift). The fast-response temperature has been calibrated against the temperature measured by the Rosemount resistance wire thermometer ${ }^{9}$ which has a slower response, but is less susceptible to drift. Taking into account the differences in response time, the two temperatures typically differ by only $\pm 0.1^{\circ} \mathrm{C}$ to $0.4^{\circ} \mathrm{C}$.

One of the goals of this experiment was to see if ozone is conservative enough to be used as a tracer along with other conservative quantities in entrainment studies. Figure 7 shows ozone concentration (O3F50) plotted against the total-water mixing ratio (QTOT) for the 6-mb sounding segment shown in the preceding figure. The separation between each data point is $0.05 \mathrm{~s}$ or $\sim 5 \mathrm{~m} .{ }^{10}$ As can be seen the data points tend to fall

${ }^{6}$ The fluctuations in the total-water mixing ratio are, at least in part, due to drift in the Lyman-alpha hygrometer calibration. We have used the Lyman-alpha data rather than the more stable dew-point hygrometer for water vapor mixing ratio because the Lyman-alpha has a faster response time. The Lyman-alpha also sometimes gives erroneous values in clouds due to wetting.

${ }^{7}$ For example, if the water vapor mixing ratio is $8 \times 10^{-3}$ measured with 5 percent accuracy, then the corresponding error in $\theta_{e}$ is about 1 $\mathrm{K}$, whereas if the liquid water mixing ratio is $0.5 \times 10^{-3}$ measured with 20 percent accuracy, then the corresponding error in $\theta_{L}$ is only $0.25 \mathrm{~K}$.

${ }^{8}$ Manufactured by Particle Measuring Systems, Inc.

${ }^{9}$ Manufactured by Rosemount Engineering, Inc.

${ }^{10}$ The ozone data have been shifted backwards by $0.2 \mathrm{~s}$ to correct for time lag due to the transit time of the air through the inlet duct to the sensor located in the cabin, and to the location of the inlet, a few meters downstream from the sensor locations for other turbulence variables (Lenschow, et al., 1982). 

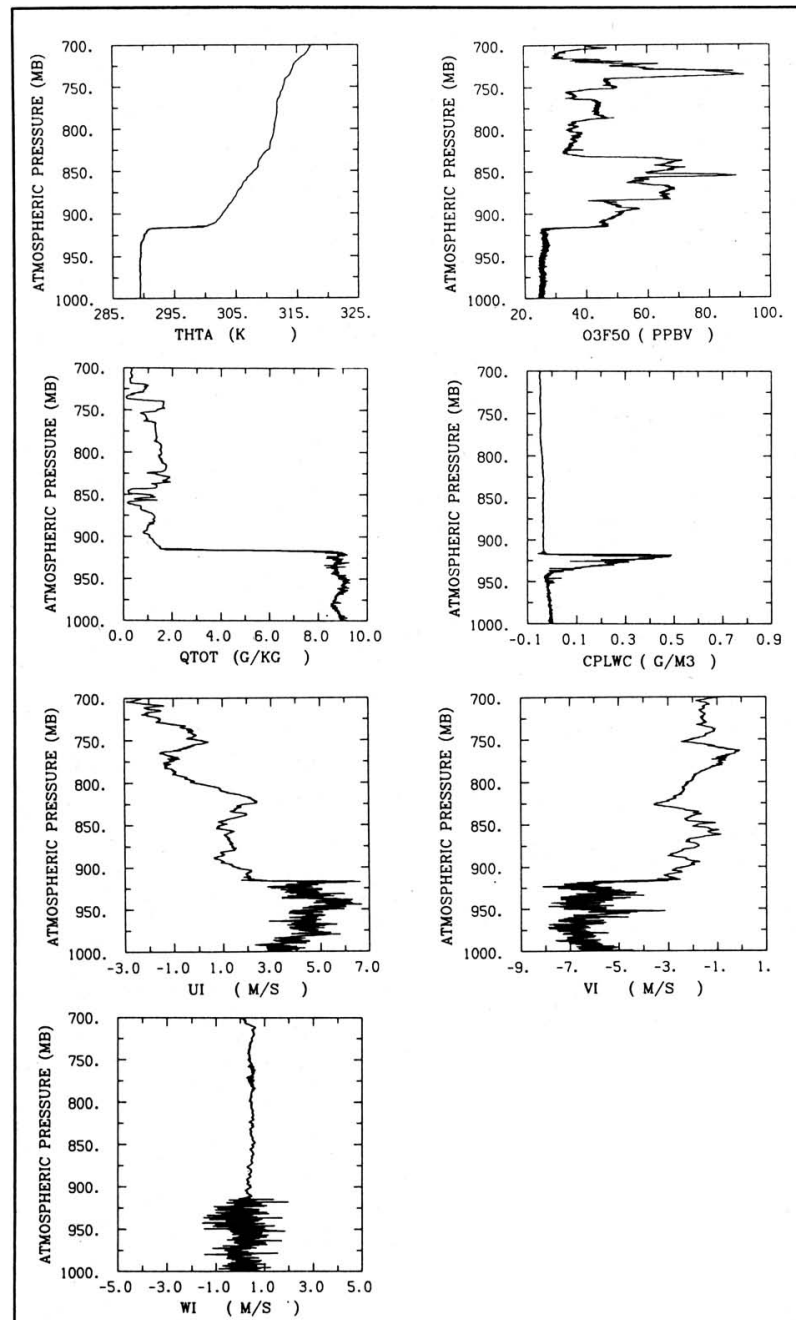

Figure 5

FIG. 5. Profiles of potential temperature (THTA), ozone mixing ratio (O3F50), water substance (vapor plus liquid) (QTOT), liquid water (CPLWC), west wind component (UI), south wind component (VI) and vertical wind component (WI) from the Electra aircraft sounding obtained at $31.4^{\circ} \mathrm{N}, 122.0^{\circ} \mathrm{W}$ from 17:50 to 18:04 UTC. The aircraft was descending at a heading of $254^{\circ}$.

along a straight line, characteristic of mixing of conservative properties. Figure 7 also shows the same ozone data plotted against the liquid-water potential temperature (THTAL). Here the line formed by the data points curves slightly at each end: toward higher temperatures at high ozone concentrations, i.e., in the upper, clear-air portion of the sounding, and toward lower temperatures at low ozone concentrations, i.e., in the lower, cloudy portion of the sounding. It is suspected that this shift is caused by radiative processes, since the liquid-water potential temperature is not conserved during radiative cooling. We have found data segments where, unlike in Fig. 7, the variables are very poorly correlated. This poor correlation may reflect errors in measurements, or may indicate the presence of sources and sinks operating on a time scale comparable to that of the mixing process.

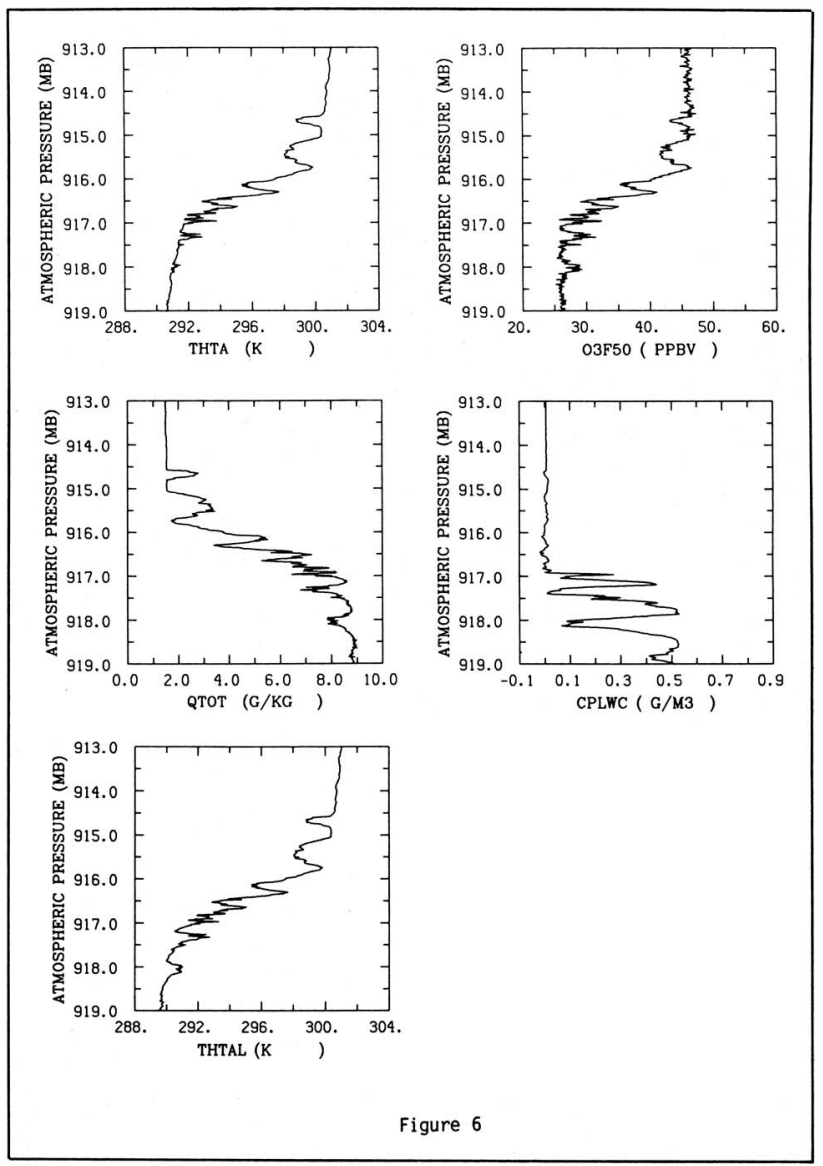

FIG. 6. More detailed profiles across the inversion capping the cloudcapped mixed layer from the sounding shown in Fig. 5. THTAL is liquid-water potential temperature.

Studies of the behavior of ozone, total-water mixing ratio and liquid-water potential temperature during mixing at the inversion are now in progress. Lenschow et al. (1988) have used measurements of wind components, temperature, humidity, liquid water, and ozone from Electra flight legs at cloud top to investigate the fine-scale structure in the vicinity of the inversion capping the boundary layer. Weaver (1987) presents many more examples of mixing-line analyses using ozone, equivalent potential temperature and water vapor from the aircraft sounding data. He also examines the impact of horizontal inhomogeneities on the determination of the average jump in scalar quantities across the top of the boundary layer, which is used in estimating the entrainment rate. He uses two complementary techniques to study the jump: one is to use the data from slant ascent and descent (sawtooth) flight legs through the boundary layer top, which gives a detailed profile at one location; the other is to use data from horizontal flight paths at cloud-top, which gives as many as 15 to 30 penetrations of the boundary layer top along a 25 to $50 \mathrm{~km}$ flight leg, but with limited vertical extent.

This jump is used, along with estimates of the turbulence flux at the top of the boundary layer of the same scalar quantity, to estimate the entrainment velocity (Lilly, 1968) through the top of the boundary layer. The entrainment velocity is the rate at which air from above the boundary layer is engulfed and mixed into the boundary layer by turbulence processes at 

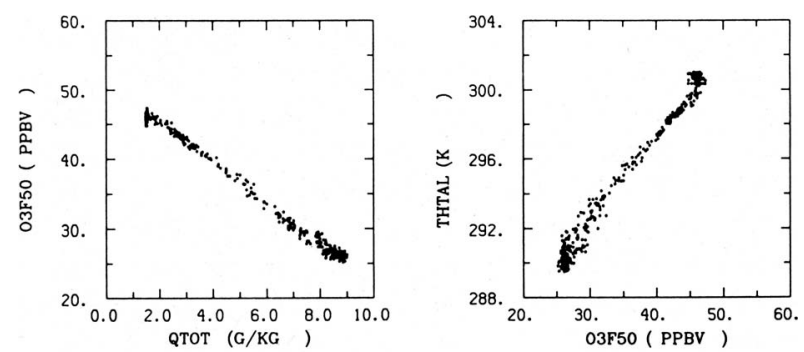

Figure 7

FIG. 7. (left) Plot of ozone (O3F50) versus water substance (QTOT); (right) Plot of liquid-water potential temperature (THTAL) versus ozone for the sounding shown in Fig. 6.

the top of the boundary layer. The flux at the boundary layer top is obtained by extrapolating flux measurements from several levels within the boundary layer to its top. The average value of entrainment velocity for flights on cloudy days obtained from ozone measurements is about $2 \mathrm{~mm} \cdot \mathrm{s}^{-1}$, with a range of 1 to $5 \mathrm{~mm} \cdot \mathrm{s}^{-1}$. ${ }^{11}$

Ozone is removed by chemical reactions at the earth's surface. This removal process is commonly parameterized for modeling purposes by assuming that various surfaces can be characterized by an ozone deposition velocity, which is the ratio of the turbulence flux of ozone in the surface layer to the mean ozone concentration at some reference level in the surface layer (e.g. Wesely, 1983). Kawa and Pearson estimate a typical value of ozone deposition velocity from the DYCOMS flights of 0.3 $\mathrm{mm} \cdot \mathrm{s}^{-1}$ with a range between 0.1 and $0.5 \mathrm{~mm} \cdot \mathrm{s}^{-1}$. The deposition rate for trace species depends not only on the rate at which molecules that strike the surface remain there; it also depends upon how efficiently the turbulence eddies in the surface layer can tranisport the trace species to the surface. For this reason, the concept of resistances (in analogy to electrical resistance) has been developed. The effects of the surface are incorporated in a surface resistance, and the effects of surface layer turbulence are incorporated into an aerodynamic resistance; the sum of the resistances is equal to the inverse of the deposition velocity. In this way, the effects of the surface can be isolated from atmospheric variations. For DYCOMS, Kawa and Pearson found a typical value for surface resistance of 2800 $\mathrm{s} \cdot \mathrm{m}^{-1}$ with a range of 1900 to $10000 \mathrm{~s} \cdot \mathrm{m}^{-1}$. Since this is more than an order of magnitude larger than a typical aerodynamic resistance, the aerodynamic resistance can be considered negligible over the ocean. On the basis of enclosure and laboratory studies, Galbally and Roy (1980) estimated the average oceanic surface resistance to be about $1000 \mathrm{~s} \cdot \mathrm{m}^{-1}$; Lenschow et al. (1982) used eddy-correlation measurements of

\footnotetext{
${ }^{11}$ Estimates of the entrainment velocities for most of the days have been obtained by R. Kawa and R. Pearson, Jr.; they are presently preparing a manuscript on their results. They have also obtained estimates of the ozone flux at the surface by a similar extrapolation of the boundary layer flux measurements to the surface.
}

ozone flux from an aircraft over the Gulf of Mexico and the North Pacific Ocean to obtain surface resistances in the range of 1700 to $1900 \mathrm{~s} \cdot \mathrm{m}^{-1}$.

\section{Chemical measurements, data and results}

One of the main objectives of DYCOMS was to study the sources, sinks, transport, and transformations of trace reactive species in a situation where the boundary layer was relatively steady-state, horizontally homogeneous, and pristine, with a well-defined capping inversion. These conditions, which are imposed to simplify the measurement strategies required to carry out a chemistry experiment, are at least partially met for this experiment. A detailed study of a particular species cannot be carried out without knowledge of other species with which it reacts and the products of these reactions. Therefore, studies of trace reactive species involve families of species. In the following sections, we deal with measurements of species from both the sulfur and the nitrogen families. As discussed by Andreae (1985) for sulfur, and Logan (1983) for nitrogen, both families have significant natural and anthropogenic sources. The magnitudes of the sources and sinks are, however, subject to considerable question.

We also include in this discussion measurements of the radionuclides radon and ${ }^{210} \mathrm{~Pb}$. Radon, which is the parent of ${ }^{210} \mathrm{~Pb}$, is not chemically reactive. However, it is emitted by the earth's crust, and therefore is a surrogate for other gaseous species emitted at the earth's surface. Similarly, ${ }^{210} \mathrm{~Pb}$ can be used as a tracer of particulates in the boundary layer.

\section{a. Sulfur gas measurements}

Carbonyl sulfide (OCS), sulfur dioxide $\left(\mathrm{SO}_{2}\right)$, and dimethyl sulfide (DMS), were determined by gas chromatography with flame-photometric detection. Cyrogenic enrichment was used to decrease lower limits of detection to about 25 parts per trillion by volume of moist air (pptv) for a sample size of one standard liter (Maroulis, 1980; Torres et al., 1980; Thornton et al., 1986). Problems with calibration-standard stability limit the absolute accuracy of OCS data to \pm 15 percent; however, the precision for one flight was better than 5 percent.

Carbon disulfide $\left(\mathrm{CS}_{2}\right)$ was collected on Carbosieve B (an adsorbent material used for concentrating atmospheric trace gases) and returned to the laboratory for analysis by gas chromatography-mass spectrometry. ${ }^{12}$ Lower limits of detection averaged 2 pptv per liter of sample. For a typical sample size of $5 \mathrm{~L}$, the lower limit of detection was 0.4 pptv.

Carbonyl sulfide was measured only on Flights 3 and 4 . For Flight 3,18 measurements in the free troposphere averaged $520 \mathrm{pptv}$ with a standard deviation of $42 \mathrm{pptv}$. In the boundary layer 25 determinations averaged $497 \mathrm{pptv}$ with a standard deviation of $46 \mathrm{pptv}$. For this Flight, free tropospheric OCS was greater than boundary layer OCS for confidence levels less than the 92 percentile. For flight 4,10 measurements in the free troposphere had a mean of $520 \mathrm{pptv}$ with a standard de-

\footnotetext{
${ }^{12}$ An isotopically labeled standard was used to increase precision by compensating for the effect of analyte loss and changes in sensitivity (Tucker, 1984; Bandy et al., 1985).
} 
viation of 25 pptv. In the boundary layer, 19 measurements yielded a mean of 500 pptv with a standard deviation of 29 pptv. Free tropospheric values of OCS were greater than boundary layer values for confidence levels less than the 90 percentile.

This limited data set suggests that OCS levels may be smaller in the boundary layer than in the free troposphere. The difference is small and should be interpreted with caution; however, one interpretation is that the ocean was a sink for OCS during the experimental period. Additional measurements with improved precision will be needed to resolve this question.

Sulfur dioxide concentrations in the boundary layer ranged from less than 20 pptv (the detection limit) to 100 pptv with a median value of about $40 \mathrm{pptv}$. Cloud and below cloud levels were not statistically different. Day-to-day variability was large, but on a time scale of a few hours, variability was fairly small $( \pm 30 \mathrm{pptv})$ and could have been instrumentally induced, since many measurements were near the detection limit. Measurable values of $\mathrm{SO}_{2}$ were found only occasionally above the boundary layer. Dimethyl sulfide concentrations ranged from less than $25 \mathrm{pptv}$ (the detection limit) to $150 \mathrm{pptv}$ with a median value of 40 pptv. Much greater variability was observed for DMS compared to $\mathrm{SO}_{2}$ for time scales of both a few hours and a few days. Although some DMS measurements were near the detection limit, there were considerably fewer cases near the detection limit than for $\mathrm{SO}_{2}$. Dimethyl sulfide above the boundary layer was consistently below the detection limit. Carbon disulfide was the only sulfur gas determined with a lower limit of detection less than 1 pptv. Boundary layer concentrations were rather uniform at about 7 pptv. In contrast, free tropospheric values just above the boundary layer averaged 25 pptv. We observed this pattern in which free tropospheric concentrations were several times boundary layer levels for every suitable flight (i.e., flights in which the boundary layer was well-capped) after Flight 6. Clearly, carbon disulfide constitutes a significant fraction of the reactive sulfur gas component in the stratocumulus boundary layer. The origin of carbon disulfide in the free troposphere is unknown. One hypothesis is that it has been transported from continental areas where it originates from anthropogenic sources.

\section{b. Nitrogen compounds}

We measured nitric acid vapor and aerosol nitrate by filter pack methodology (Goldan et al., 1983). The period of collection varied between one-half to one hour. Just above the cloud-top inversion, we found an average of 278 pptv of nitric acid vapor and $6 \mathrm{pptv}$ of aerosol nitrate. Within the boundary layer, there was much less vapor (only $40 \mathrm{pptv}$ ), but more aerosol (24 pptv). Thus, the total nitrate above the inversion averaged more than four times that within the boundary layer-a very significant difference.

Subsequent tests of our curved intake system suggest that the marine boundary layer aerosol data should be viewed as lower limits to the actual aerosol concentrations, due to the possibility that some particles may have been lost in the intake system. If we could correct for these losses, the difference across the inversion would be somewhat reduced, but certainly not by more than 30 percent. The actual percent aerosol nitrate (relative to total nitrate) in the free troposphere is probably close to the observed 2 percent, but the boundary layer nitrate might be as much as 55 percent aerosol. (We observed 38 percent.)
On the basis of the large difference across the boundary layer top and entrainment velocities derived from the ozone measurements, we estimated that the average flux of nitrate from the free troposphere to the boundary layer during Flights 1, 2, 3, 4,5 , and 10 (days when the boundary layer appeared to be well mixed and strongly capped) to be $1.2 \pm 1.0 \mathrm{ng}\left(\mathrm{NO}_{3}\right)$. $\mathrm{m}^{-2} \cdot \mathrm{s}^{-1}$. If it is assumed that the concentration was in steady state and horizontally homogeneous (neither assumption could be adequately tested), and that there was no source or sink of nitrate within the marine boundary layer, the flux into the top of the boundary layer would be equal to the deposition of nitrate at the ocean surface. If it is assumed that contributions from precipitation are negligible, the resulting deposition velocity is $1.1 \pm 1.0 \mathrm{~cm} \cdot \mathrm{s}^{13}$

A refurbished high sensitivity $\mathrm{NO} / \mathrm{NO}_{x}$ instrument was configured to alternately measure $\mathrm{NO}$ and $\mathrm{NO}_{x}$ based on chemiluminescence with ozone. Failure of the ozonizer, and only partially successful repair, together with intake system problems, limited the ability to zero the instrument with enough precision to obtain accurate measurements in the clean air environment. The major positive results obtained were the large and rapid increases in $\mathrm{NO}_{x}$ observed when the flight path intercepted a ship's plume, and when returning to the polluted San Diego air basin.

We also used modified Mohnen slotted rods to collect cloud water for analysis (Huebert et al., 1988). Even at several hundred kilometers offshore in relatively clean air, we found the water to be surprisingly acidic-observed pH's ranged from 3.71 to 5.06 , with a median value of 4.02 . Generally there was more total sulfate than nitrate in the cloud water, but the molar ratio of non-seasalt sulfate to nitrate averaged 0.8 .

The chemistry of cloud water was often quite different at various levels within cloud. We do not yet understand why; possible causes include effects of enhanced condensation and evaporation near cloud top due to entrainment, the vaporization of some nitric acid as the acidic droplets evaporate in outflow regions, and possible sampling artifacts related to changes in liquid water content throughout the cloud.

\section{c. Radionuclides}

We collected radon samples by pumping ambient air into aluminum cylinders to a pressure of about $1100 \mathrm{psi}\left(7.58 \times 10^{6}\right.$ $\mathrm{Pa}$ ), which corresponds to a sample size of about 1 or $2 \mathrm{~kg}$. Radon was preconcentrated on activated charcoal at $200 \mathrm{~K}$ and then transferred to Lucas cells where it was determined by alpha-scintillation spectrometry. The precision of these determinations was about 0.5 atoms $\cdot 1^{-1}$. Boundary layer radon concentrations ranged from 17 to 415 atoms $\cdot 1^{-1}$. Radon levels just above the boundary layer were in the range 13 to 620 atoms $\cdot 1^{-1}$. The lowest values correspond to cases in which radon came primarily from the ocean, with the continental contribution having decayed to an insignificant amount. The larger values of 200 to 600 atoms $\cdot 1^{-1}$ definitely resulted from transport of radon from continental areas. Even the larger values, however, were substantially below radon levels in continental boundary air, which are typically $\sim 1800$ atoms $\cdot 1^{-1}$

\footnotetext{
${ }^{13}$ Based on previous laboratory and atmospheric studies of the deposition of nitric acid vapor to a sea surface in the presence of light to moderate winds, this seems reasonable (Huebert, personal communication).
} 
(Liu et al., 1984). Since the decay rate for radon is $2.098 \times 10^{-6}$ $\mathrm{s}^{-1}$ (i.e., a half-life of $\sim 3.8$ days), this suggests that substantial dilution and decay of the continental-air radon had occurred before reaching the DYCOMS test site.

${ }^{210} \mathrm{~Pb}$ was sampled by collecting aerosols on large filter media which were returned to the laboratory for analysis. The ${ }^{210} \mathrm{~Pb}$ was allowed to decay to ${ }^{210} \mathrm{Po}$, which was then analyzed by autodeposition on silver followed by energy dispersive alpha spectroscopy analysis. Precision and accuracy were increased dramatically by adding ${ }^{208} \mathrm{Po}$ as an internal standard. Repeated analysis as a function of time over a one-year period provided a correction for ${ }^{210} \mathrm{Po}$ present in the atmosphere at the time of sampling. Levels of ${ }^{210} \mathrm{~Pb}$ were in the range of 40 to 300 atoms $\cdot 1^{-1}$. Generally, levels were higher in the free troposphere than in the boundary layer. Analyzed in steady state the ${ }^{210} \mathrm{~Pb}$ data yielded dry deposition velocities, assuming negligible wet deposition, of $\sim 0.4 \mathrm{~cm} \cdot \mathrm{s}^{-1}$. This value seems somewhat high. Generally, in situations when both wet and dry deposition are significant, the total deposition velocity is more like $0.6 \mathrm{~cm} \cdot \mathrm{s}^{-1}$. The data suggest that either dry deposition may be much more important over oceans than previously thought, or precipitation, indeed, does contribute significantly to deposition in this stratocumulus regime.

\section{Budgets}

\section{a. Ozone and meteorological scalars}

One of the main objectives of DYCOMS was to obtain budgets of scalar variables for which turbulence fluxes could be measured (ozone, total water, and sensible heat), and to use the entrainment rates obtained from these scalars to estimate budgets of trace species for which only mean values can be measured. R. Kawa and R. Pearson, Jr. are carrying out analyses of the scalar budgets for which turbulence fluxes can be measured. Previously, Lenschow et al. (1981) performed an overland ozone budget case study. The dominant budget terms in a well-mixed boundary layer are the rate of change with time, horizontal advection, vertical flux divergence, and the internal sources and sinks (e.g., chemical, phase change, precipitation, and radiation). Two flight patterns were used during DYCOMS; both were advected with the wind to avoid having to measure the advective term in the budget equations. The first was a series of stacked crosswind legs at different levels throughout the boundary layer, each of 15 minutes duration. To avoid contamination by engine exhaust, all turns were made upwind. We assumed that the horizontal gradients would not be large enough to affect the budgets due to this small horizontal displacement. In practice, the observed gradients in ozone were so large that this displacement contributed a significant term to the budget. Therefore, the flight legs were modified in later flights to include both crosswind and alongwind " $L$ " shaped legs so that the horizontal advection term due to the small horizontal displacement of subsequent legs could be included in the budget. For sensible heat and total water, this term was relatively much smaller.

We assumed that the marine stratocumulus environment was reasonably close to steady state. This assumption is useful for evaluating budgets of reactive species which cannot be mea- sured at turbulence rates. Preliminary analysis of the ozone budget by R. Kawa and R. Pearson, Jr. indicates that the total time derivative is essentially zero when averaged over all the cases, in accordance with this assumption, but that in individual cases the ozone time rate-of-change term was significant, and of either sign. Solving the budget equation for the chemical source-sink term (e.g., Lenschow et al., 1981), and averaging over all the cases for which budgets could be estimated, result in the suggestion of a very weak sink that is consistent with the expected photochemistry of a mixed layer far from anthropogenic pollution sources.

Their analysis of the sensible heat budget shows a small increase in temperature for all cases in which the budget could be estimated, probably due to the increasing sea surface temperature along the air trajectory. In addition, they found a small source term that may originate from radiative heating (either solar or infrared, or both) of aerosols (including both cloud droplets and particulates) in the mixed layer. The mean humidity also increases along the trajectory, as expected; furthermore, the total-water budgets are very close to being balanced.

\section{b. Radon and sulfur}

Once the entrainment rate is obtained from analysis of mean and turbulent flux data for a conserved scalar variable, it is then possible to investigate budgets of trace species for which only mean measurements are possible. For these species, neither the internal (e.g. chemical) source-sink term nor the surface-flux term are measurable from the aircraft. Therefore, to evaluate their budgets, some additional information about one or the other of these terms is necessary. For radon, for example, a mean oceanic emission flux can be assumed, which is a small fraction of the continental emission rate. We also assume a horizontally homogeneous, well-mixed boundary layer with a well-defined capping inversion, although as indicated above, horizontal homogeneity is not a good assumption for ozone. At this time, we do not know how important the horizontalgradient term may be in budgets of radon and sulfur species since the instrumentation integration times were too long to resolve horizontal variability. We did find that the time rateof-change term, even in this relatively steady-state, benign environment, is large for both ozone and radon, and varies in both sign and magnitude from day to day. Clearly, the time rates of change need to be measured in order to study the budgets of trace species.

Limitations in measuring the time rate-of-change term may be the result of limitations on either instrument accuracy or sampling strategy, or both. For sulfur gases in DYCOMS, instrumentation limitations were important. As an example, with a DMS concentration of 30 pptv as was typical of DYCOMS, the measurement precision was estimated to be about 30 percent. With a time difference between sets of legs of 7200 $\mathrm{s}$, and a boundary layer height of $1000 \mathrm{~m}$, again as typical of DYCOMS, the propagated error in the time derivative is $6.1 \times 10^{13}$ molecules $\cdot \mathrm{m}^{-2} \mathrm{~s}^{-1}$. Andreae et al. (1985) estimate an overall ocean emission of $42 \mathrm{Tg}(\mathrm{S})$ /year, which corresponds to a surface flux of $9 \times 10^{13}$ molecules $\cdot \mathrm{m}^{-2} \mathrm{~s}^{-1}$. This is comparable to the estimated instrumental error in measuring the time derivative. For ozone and radon, instrumentation accuracy is considerably better, but the two hour time interval between the sets of flight legs was still insufficient to accurately resolve 
the time variation during an individual flight. Based on our DYCOMS results, we estimate that a time interval several times as long would be desirable. We also note that roughly an orderof-magnitude improvement in the measurement precision of sulfur species is now possible with the use of a gas chromatography mass spectrometric method utilizing isotopically labelled standards (GC/MS/ILS).

\section{Conclusions}

The meteorological conditions encountered during DYCOMS were typical of the summertime marine stratocumulus regime off the California coast. Although much of the data analyses are still in progress, some results are available. Ozone has been proven to be a useful conserved tracer for entrainment studies, and measurements of the turbulence flux and vertical profile of ozone have been used for estimating the entrainment velocity at the top of the boundary layer and deposition at the ocean surface. The airplane measurements have also been used to estimate budgets of ozone, sensible heat, and total water.

Mean measurements of sulfur and nitrogen species, and radon were obtained in this relatively pristine environment, both below, within, and above the stratiform cloud capping the boundary layer. The DYCOMS chemical sampling program generated numerous questions about cloud chemistry (e.g. differences in the chemistry of cloud water as a function of height within cloud), aerosol chemistry in the marine boundary layer (e.g. effects of losses in the aerosol probe intake system) and airborne sampling methodologies (e.g. how to more accurately measure time rates of change and horizontal gradients of trace species). These are now serving as the seeds for subsequent generations of observational studies.

Acknowledgments. We appreciate the outstanding effort put into this program by the staff of the Research Aviation Facility, both in planning and carrying out the field program, as well as in the subsequent data processing effort. We also thank the staff at the North İsland Naval Air Station for their cooperation and interest in the experiment. We thank Joyce Harris for computing the parcel trajectories for each of the DYCOMS flights, Len Fedor for providing the surface temperature distribution data (Fig. 1) and Howard Hanson for providing the satellite pictures (Figs. 3 and 4). We appreciate the interest and support of Jarvis Moyers throughout the entire effort, and acknowledge support from NSF Grants ATM-3811099, -8612745, and -8403049.

\section{References}

Albrecht, B. A., D. A. Randall, and S. Nicholls, 1988: Observations of marine stratocumulus during FIRE. Bull. Amer. Meteor. Soc., 69, 618-626.

Andreae, M. O., 1985: The emission of sulfur to the remote atmosphere. In The Biogeochemical Cycling of Sulfur and Nitrogen in the Remote Atmosphere, edited by J. N. Galloway, R. J. Charlson, M. O. Andreae and H. Rodhe, D. Reidel, Hingham, MA, 5-25.

Andreae, M. O., R. J. Ferek, F. Bermond, K. P. Byrd, R. T. Engstrom,
S. Hardin, P. D. Houmere, F. LeMarrec, H. Raemdonck, and R. B. Chatfield, 1985: Dimethyl sulfide in the marine atmosphere. $J$. Geophys. Res., 90, 12891-12900.

Bandy, A. R., B. J. Tucker, and P. J. Maroulis, 1985: Determination of part-per-trillion by volume levels of atmospheric carbon disulfide by gas chromatography/mass spectrometry. Anal. Chem., 57, 13101314.

Galbally, I. E. and C. R. Roy, 1980: Destruction of ozone at the earth's surface. Quart. J. Roy. Meteor. Soc., 106, 599-620.

Global Tropospheric Chemistry: A Plan for Action, Global Tropospheric Chemistry Panel, Board of Atmospheric Sciences and Climate, National Academy Press, Washington, D.C. 20418, 1984, 194 pp.

Goldan, P. D., W. C. Kuster, D. L. Albritton, F. C. Fehsenfeld, P. S. Connell, R. B. Norton, and B. J. Huebert, 1983: Calibration and tests of the filter collection method for measuring clean-air, ambient levels of nitric acid. Atmos. Environ., 17, 1355-1364.

Harris, J. M., 1982: The GMCC Atmospheric Trajectory Program, NOAA Technical Memorandum ERL ARL-116, Air Resources Laboratories, Rockville, MD, $30 \mathrm{pp}$.

Huebert, B. J., S. VanBramer, and K. L. Tschudy, 1988: Liquid cloudwater collection using modified Mohnen slotted rods. J. Atmos. Chem., 6, 251-263.

Lenschow, D. H. and L. Kristensen, 1988: Applications of dual aircraft formation flights. J. Atmos. and Oceanic Tech., in press.

Lenschow, D. H., R. Pearson, Jr., and B. B. Stankov, 1981: Estimating the ozone budget in the boundary layer by use of aircraft measurements of ozone eddy flux and mean concentration. J.Geophys. Res., 86, 7291-7297.

Lenschow, D. H., R. Pearson, Jr., and B. B. Stankov, 1982: Measurements of ozone vertical flux to ocean and forest. J. Geophys. Res., 87, 8833-8837.

Lenschow, D. H., 1984: Instrumentation development needs for use of mass-balance technique. A chapter in Global Tropospheric Chemistry-A Plan for Action, Global Tropospheric Chemistry Panel, National Academy Press, Washington, D.C., 141-143.

Lenschow, D. H., 1986: Aircraft measurements in the boundary layer. Probing the Atmospheric Boundary Layer, D. H. Lenschow, Ed., Amer. Meteor. Soc., 39-55.

Lenschow, D. H., V. Patel, and A. Isbell, 1988: Measurements of fine-scale structure at the top of marine stratocumulus. Preprint Volume, 8th Symposium on Turbulence and Diffusion, 25-29 April 1988, American Meteorological Society, Boston, MA.

Lilly, D. K., 1968: Models of cloud-topped mixed layers under a strong inversion. Quart. J. Roy. Meteor. Soc., 94, 292-309.

Liu, S. C., J. R. McAfee, and R. J. Cicerone, 1984: Radon 222 and tropospheric vertical transport. J. Geophys. Res., 89, 7291-7297.

Logan, J. A., 1983: Nitrogen oxides in the troposphere: Global and regional budgets. J. Geophys. Res., 90, 10463-10482.

Maroulis, P. J., 1980: Gas chromatographic methods for atmospheric sulfur dioxide and carbonyl sulfide at the part-per-trillion level. Ph.D. Dissertation, Drexel University, Philadelphia, PA.

Nicholls, S., 1984: The dynamics of stratocumulus: Aircraft observations and comparisons with a mixed layer model. Quart. J. Roy. Meteor. Soc., 110, 783-820.

Randall, D. A., J. A. Coakley, Jr., C. W. Fairall, R. A. Kropfli, and D. H. Lenschow, 1984: Outlook for research on subtropical marine stratiform clouds. Bull. Amer. Meteor. Soc., 65, 1290-1301.

Thornton, D. C., A. B. Driedger III, and A. R. Bandy, 1986: Determination of part-per-trillion levels of sulfur dioxide in humid air. Anal. Chem., 58, 2688-2691.

Torres, A. L., P. J. Maroulis, A. B. Goldberg, and A. R. Bandy, 1980: Atmospheric OCS measurements on project GAMETAG. $J$. Geophys. Res., 85, 7357-7360.

Tucker, B. J., 1984: Measurements of atmospheric carbon disulfide using aircraft platforms and GC/MS isotopic dilution analysis technique, Ph.D. Dissertation, Drexel University, Philadelphia, PA. 
Weaver, C., 1987: Observational analysis of cumulus and stratocumulus entrainment using ozone. Ph.D. Thesis, Colorado State University. (Also available from Dept. of Atmospheric Science, Colorado State Univerity, Fort Collins, CO as Atmospheric Science Paper No.
422.) $114 \mathrm{pp}$.

Wesely, M. L., 1983: Turbulent transport of ozone to surfaces common in the eastern half of the United States. Trace Atmospheric Constituents. Edited by S. E. Schwartz, J. Wiley and Sons, 345-370.

announcements (continued from page 1057)

Tidal Analysis and Prediction Techniques; Tidal Hydrodynamics Phenomena and Modeling; Nonlinear Tidal Interactions In Shallow Water; Internal Tides and Baroclinic Effects; New Approaches To Tidal Data Acquisitions; and Tidal Applications, Products, and Services. Each session will begin with one or more review papers describing our present knowledge in that area of tidal theory, modeling, analysis, etc. The program has been carefully organized to be comprehensive and to cover all state-of-the-art developments, including tidal detection from satellites, nonlinear tidal interaction, global modeling, and new products and services resulting from recent developments in computer technology, telecommunications, and numerical modeling. One objective of the conference is to produce a refereed volume that can serve as a reference on the tides.

Early registration is recommended because space will be limited. Direct all inquiries to: Dr. Bruce Parker, Chairman Steering Committee, International Conference On Tidal Hydrodynamics, N/OMA13, Room 414, National Ocean Service, NOAA, 6001 Executive Blvd., Rockville, MD 20852, or call (301) 443-8768/8060.

\section{Fellows Program Offered by National Council of Industrial Meteorologists}

For a second year, The National Council of Industrial Meteorologists (NCIM) is continuing its private sector meteorology fellows program to increase the awareness of the opportunities in the industrial meteorology consulting field. The program will match two senior-level meteorology or atmospheric sciences students with private meteorologists or meteorological consulting companies for a summer of practical work experience.

The employers will pay a salary and the NCIM will provide a grant of $\$ 1,500$ to each student. College students at junior level or higher interested in applying for the program, and companies or consultants who would be willing to sponsor a student for the summer of 1989 are asked to write the NCIM Student Intern Committee Chairman for applications or information. The applications must be received no later than 30 November 1988. Contact Robert G. Fisher at 1839 Crafton Road, North Palm Beach, Florida 33408, or telephone (407) 627-4062 for more details.

\section{International Course on Tropical Ocean- Atmosphere Interactions}

An International Course on Tropical Ocean-Atmosphere Interactions, organized by the Institute de Pesquisas Espaciais, Fundaão Cearense de Meteorologia e Recursos Hidrícos and the Universidade Federal do Ceará, will be held 13 February10 March 1989 in Fortaleza, Brazil.

The objectives of the course will be to review, present and discuss theories, observations, and modeling of the interactions of the coupled ocean-atmosphere system and their effects on climate. The course will focus on climate predictability in time scales ranging from a month to a few years. Ocean-atmosphere interactions in the tropical Pacific and
Atlantic Oceans which lead to climatic fluctuations over the global Tropics will be reviewed with emphasis on climatic anomalies in Tropical South America and Africa.

The main topics will be observations of the mean structure and variability of the tropical atmospheric and oceanic circulations; theories of the large-scale atmospheric circulation in the tropics; theories of tropical oceans circulation; El NiñoSouthern Oscillation; the Atlantic Ocean; GCMs, data, and instruments; climate predictability.

The activity will be based on lectures and seminars given by visiting experts and participants. The principal lecturers will be Mark Cane of Lamont-Doherty Geological Observatory, and Edward Sarachik of the University of Washington.

The course is open to graduate students and research workers in meteorology, oceanography, physics, mathematics, and related sciences. Participants are encouraged to submit contributions in their field of research.

The closing date for requesting participation is 30 November 1988. Financial aid for participation will be available on a very limited basis; closing date for requesting financial aid is 31 October 1988. For applications and additional information, contact Carlos A. Nobre, Course on Tropical Ocean-Atmosphere Interactions CPTEC/INPE, Caiza Postal 515, 12201 São José Campos SP, Brazil (tel.:123229977 Ext. 270; Telex 1233530 INPE BR; Telemail [INPE.MET/OMNET]MAIL/ USA.

\section{FOF/SSSF Changes Meeting Date}

The dates for the meeting of the Advisory Panel for the Field Observing Facility and Surface and Sounding Systems Facility (FOF/SSSF) have changed. The original dates were from 1 October 1990 through 1 April 1991; the new dates are from 1 October 1989 through 1 April 1990. See April 1988 BULLETIN (p. 372) for further information.

\section{$4^{\text {th }}$ International Conference on Aerobiology}

The IAA announces the $4^{\text {th }}$ International Conference on Aerobiology, to be held 3-7 September 1990 in Stockholm, Sweden.

The conference program will focus on topics including the significance of air pollution in aerobiology; aeroallergens; meteorological aspects of aerobiology; ecological aspects of aerobiology; bio-aerosols indoors; methodology, sampling, and analyzing; microbiology and palynology; and phytopathology.

For further information on registration and paper deadlines, write to the Administrative Secretary, $4^{\text {th }}$ International Aerobiology Conference, Konferensservice AB, Box 40037, S0171 04 SOLNA, Sweden; Telex 12754 SINIAB S. 